\title{
Blood Donation, Payment, and Non-Cash Incentives: Classical Questions Drawing Renewed Interest
}

\author{
Alena M. Buyx \\ The Harvard Program in Ethics and Health, Harvard Medical School, Boston, MA, USA
}

\section{Key Words}

Blood donation - Medical ethics · Incentives .

Altruism · Choice architecture

\section{Summary}

Blood is scarce, and ensuring a sufficient blood supply remains difficult for many countries. Payment for blood as a strategy to increase donations has remained highly controversial for decades, and the debate about ethical issues in paying donors has become somewhat stuck. At least from a policy perspective, it is important to find a compromise which allows for devising and implementing acceptable and successful policies to increase the blood supply. In this paper, such a compromise is developed both from a theoretical and empirical perspective, namely implementing well-designed non-cash incentives which cut across the rigid dichotomy of altruistic donations versus payment for donations. In order for this compromise to work, more attention to donation motives, the choice architecture, and the setting in blood donation needs to be paid.

\section{Introduction}

Ethical issues in blood donation have been discussed for a long time. One of the most controversial problems in the field has at all times been how to increase the number of donations. Blood supply has always been scarce. In recent years, some countries have experienced serious blood shortages due to, among other things, a decrease following 9/11 (after an initial surge in donation) and the attention surrounding a potential transmission risk of prion disease [1-3]. Ensuring a sufficient

\author{
Schlüsselwörter \\ Blutspende - Medizinethik - Anreize - Altruismus . \\ Entscheidungsarchitektur
}

\section{Zusammenfassung}

Es ist nach wie vor eine Herausforderung für viele Länder, eine ausreichende Versorgung mit Blutprodukten zu gewährleisten. Eine vielfach diskutierte Strategie zur Erhöhung des Blutspendeaufkommens - die bezahlte Blutspende - ist seit Jahrzehnten umstritten. Die Debatten um ethische Aspekte der bezahlten Blutspende bewegen sich in den letzten Jahren nur noch wenig; es besteht akuter Bedarf nach einem akzeptablen Kompromiss, der neue Wege zur Erhöhung des Spendeaufkommens möglich werden lässt. In diesem Beitrag wird ein solcher Kompromiss skizziert, nämlich die Einführung von Anreizen, die die eingefahrene Dichotomie zwischen altruistischer und bezahlter Blutspende umgehen und in einen umfassenden Ansatz zur Spendeförderung eingebettet sind, der Spendemotive, Spendesetting und die Entscheidungsarchitektur berücksichtigt.

blood supply remains difficult. Hence, the well-worn questions of how more people could be persuaded to become blood donors, and whether payment or other incentives could increase the blood supply, are still pressingly relevant.

Richard Titmuss' influential work «The Gift Relationship» (1971) most prominently established the dichotomy of an economic framework for blood donation with paid donors versus a solidary system of altruistic unpaid donors [4]. Ever since, the discussion of raising the number of blood donors using payment as an incentive has followed along these lines.

\section{KARGER}

Fax +497614520714

Information@Karger.de

www.karger.com (c) 2009 S. Karger GmbH, Freiburg

Accessible online at:

www.karger.com/tmh

Dr. med. Alena M. Buyx, M.A.

The Harvard Program in Ethics and Health, Harvard Medical School

François Xavier Bagnoud Building, 6th Floor

651 Huntington Avenue, Boston, MA 02115, USA

Tel. +1 617-9553721, Fax -4323721

Alena_buyx@hms.harvard.ed 
A controversial debate between proponents and opponents of paid donation has been going on for several decades now [413]. Partly in response to this debate, most countries in the developed world have abandoned paid blood donation and now have either fully altruistic donation systems or mixed systems with altruistic donation, some forms of financial compensation for expenses, and/or other incentives [14]. International regulations reflect a strong stance against paid donation systems; bodies such as the International Society of Blood Transfusion, the WHO, the European Union or the Council of Europe all call for fully altruistic donation [15-18]. Nonetheless, payment remains one of the most effective ways to raise donation rates, and several countries would not be able to fulfil their demand for blood without it. Despite this fact, the theoretical debate about paid blood donation has quieted down a bit in recent years, probably because it has become somewhat stuck. This is at least partly due to the fact that from each of the opposing sides in the controversy, it is possible to make good arguments. While such a situation is fascinating and challenging from a philosophical point of view, from a policy perspective the need for blood calls for overcoming the opposition. It is important to find a compromise which allows for devising and implementing acceptable and successful policies to increase the blood supply.

With a focus on blood donation in developed countries, a way to achieve such a compromise is sketched in this paper: namely implementing well-designed non-cash incentives which cut across the dichotomy of altruistic donation versus self-interested paid donation, while at the same time paying more attention to the motives, the choice architecture, and the setting in donation.

The term 'incentives' covers a broad range of both financial and non-financial payments, gifts, goods, or tokens. In this paper, it will be assumed that a cash payment can be distinguished from other forms of non-cash incentives in normatively meaningful ways. In the following, non-cash incentives will be understood to be any gift, good, or token, either of non-monetary value or of small monetary value, donors receive conditional on donation.

In order to develop the proposal for the implementation of these non-cash incentives, it is necessary to briefly look at the main arguments against payment and some of the classic refutations. Calling these to mind in the first part of this paper helps to understand why maintaining a rigid division between altruistic donation and paid donation will not result in realistic solutions any time soon.

\section{Debating Paid Blood Donation}

Ever since the publication of Titmuss' book, two groups of arguments have been central in debating strategies to increase blood donation by payment. The first group consists of arguments mainly addressing the potential violation of some im- portant ethical principle or some vital intrinsic value/feature of medicine or society (intrinsic/deontological arguments), while the second group focuses mainly on actual or potential consequences of the strategies in question (extrinsic/consequentialist arguments; distinction developed in [19]). Those opposing paid donation are more likely to underline arguments of the first kind, while proponents of payment do not accept their power and concentrate on refuting the arguments of the second kind.

\section{Intrinsic/Deontological Arguments}

\section{Compromised Autonomy: Coercion/Pressure?}

As in other situations of (medical) decision-making, an important consideration in any kind of donation context is donor autonomy [20]. One requirement for voluntary and informed consent is that donors should be able to make a free decision without being coerced or unduly pressured. In the case of paid blood donation, some worry that payment amounts to coercion against the donor, and hence the third requirement of informed consent and donor autonomy is compromised when donors are paid [21].

Coercion has been defined as an intentional, credible threat of harm or force to control or influence a person [22]. According to this definition, the offer of payment for blood donation cannot be considered coercion, since it is not accompanied by any kind of threat. However, it has been debated whether, depending on the circumstances of the person and the alternatives of action open to them, offers can be coercive and exert undue pressure [23, 24]. In our context this would mean that the fewer alternatives a person has to obtain the financial means offered through blood donation, the higher the coercive influence or pressure exerted through the offer of payment. If no alternatives for income present themselves, refusing the offer of payment for blood would be very unreasonable [25]. The fear of hunger, for example, can be considered coercive in this way, if no alternatives to avoid it present themselves. Thus, most agree that in poor countries it could be assumed that the poorest of donors are unduly pressured or even coerced to donate because of their extremely dire circumstances and the lack of alternatives to gain financial resources [10]. Hence, offering someone in extreme material need and without alternative opportunities for income money for blood instead of other, more meaningful options could be understood as an unacceptable way of compromising this person's autonomy.

However, there is less accord whether this holds in developed countries. Here, desperate need is thankfully a rare occasion; but whether the offer of paying for donation is potentially irresistible and 'unreasonable to refuse', particularly for those at the bottom of the socio-economic ladder, remains a matter of open debate. 


\section{Justice Concerns}

A related objection to paid donation is raised because of concerns for justice. The fact that those from lower socio-economic groups are more prevalent among paid donors has been labelled an injustice $[4,21]$.

There are two important ways in which the higher occurrence of lower socio-economic groups among paid donors could constitute an injustice: First, quite generally, it could be argued that the equivalence principle of commutative justice would be violated if those who gave blood were excluded from its distribution if they needed blood themselves. In many Third World Countries it is indeed the case that poor donors sell their blood to rich health-care systems without having the benefit of a sufficient blood supply in the event of their own need [26]. Most agree that this constitutes a clear injustice.

Within rich countries using paid systems, the same argument could be made if blood was distributed by ability to pay and had to be bought by patients in need. Such a practice would systematically disadvantage the financially worse off. Since these are more frequent among paid donors, the same violation of commutative justice would arise as in poor countries. This is actually the case in the United States. In most other developed countries, particularly in European countries with universal health care, blood is allocated according to need instead of by ability to pay. There, this particular objection against paid donation does not apply.

A second potential injustice is pointed out, namely that payment for blood is unfair because it is more attractive to those from lower socio-economic groups, who have a greater need to use this option to gain income $[4,21]$ (here, coercion comes into play again [27]). Others argue against this that while it is indeed true that cash payment for donation is more attractive to those of fewer financial means, this does not render the payment itself unjust [10] - rather, it is an instance highlighting the injustice of the underlying, substantial income inequalities in modern societies and an instance in which we find the visible effects of these income inequalities particularly troubling.

Those opposing payment argue that paid donation takes advantage of this existing injustice and thus perpetuates it. In contrast, those arguing for payment find such a worry hypocritical. In their view, as long as income inequalities are accepted, it must be accepted that payment for blood donation - as well as payment for participating in research, or payment for very unpleasant work, or payment for organ donation - will be more attractive to those of lower means. Banning payment for donation without at the same time improving the situation of those for whom it would be attractive does not make this particular injustice disappear [28]. It just makes it less visible.

The underlying ethical question of how to respond to the fact that due to income inequalities, some activities are taken up more by those with fewer financial means, is not specific to the blood donation context. It is one of the biggest, and so far unsolved, challenges to modern political philosophy and social policy.

\section{Violation of Human Dignity: Instrumentalisation/}

\section{Devaluation?}

From a Kantian perspective, some consider the offer and acceptance of payment for blood to constitute an instrumentalisation of a person, in that the paid donor becomes a mere means to the ends of others. In this view, payment for blood donation would violate the principle of human dignity. (This kind of argument has played an important role in related contexts, such as organ donation $[29,30]$.)

To many, this appears to be a powerful objection against paid donation, pointing out that some otherwise fully acceptable and even commendable social practices might get destroyed or corrupted through payment [31]. In putting a 'price' on a personal 'good' - blood -, human dignity is threatened through devaluation (some say dehumanisation [13]) of the person involved. However, it could be said that such a devaluation does not necessarily follow from paying for a certain activity or personal 'good', especially not if such a payment is accompanied by sufficient respect for the person as a dignified end in itself. The question can justifiably be raised if payment for blood would necessarily mean that the donor is treated without proper respect. After all, much depends on the setting and on how the activity of donation and the payment for it are framed - 'cash for a poor and desperate sod' or 'payment as a reward for a commendable/heroic deed'.

However, to those opposing paid donation, cash for blood always expresses a degradation [32] and lack of respect towards the donor, irrespective of the setting and of how the payment is framed, because paying a donor would highlight that the donor is in need of that payment; that through becoming part of a paid donation system, they are marked out and stigmatised as someone so desperate that they allow that a price is set on an essentially priceless 'part' of their body. This stigmatisation, it could be said, brings with it a necessary devaluation of the worth of the person and could even carry over to the whole group of paid donors. An obvious response to this is that there surely are people who accept payment for blood donation without being desperate. Furthermore, most would not consider payment for jobs in which a person does something unpleasant or something potentially harmful to their body or even endangers their life on a regular basis as necessarily putting a price on their body or life, thus lessening their value and depriving them of the respect they deserve as a dignified person. And while we especially appreciate people who do charity and pro bono work, we generally do not deprive the nurse, the physician, or the social worker of our esteem because they are paid for an activity others perform for free.

Apparently, the material question lying at the heart of the dispute over whether paid blood donation violates the dignity of those involved hinges on whether or not donating blood is seen as a 'special' kind of activity, different in relevant respects from other potentially paid activities, and in need of 'protection' from any financial transaction - a matter both controversial and, so far, largely undecided. 


\section{Extrinsic/Consequentialist Arguments}

\section{Safety Considerations}

At least in the medical literature, by far the most common objections to payment in blood donation are safety considerations. In the past, some studies have shown that paid donors have a higher risk of transfusion-transmitted infections (TTIs) [11, 33-35]. Paid donors are also more likely to disguise risk factors of infection, such as drug abuse [36, 37]. Methods of anonymous self-reporting of risks, such as the confidential unit exclusion (CUE), are unfortunately not very effective [38]. Taking a careful anamnesis of every donor has proven to be a more successful method to discover higher risks of infection [39].

A risk of compromised blood safety poses an important argument against paid donation, since it endangers recipients and can potentially have catastrophic consequences. On the other hand, such a risk is not inevitable. It has also been shown that blood quality depends far more on donation setting and established blood safety measures than on whether donors receive payment [40]. Both TTI-detecting tests as well as virus inactivation and other safety methods have developed considerably over the last years, and it can reasonably be expected that this development will continue. Transmission rates in countries with good blood safety measures have already become very low, irrespective of donor type [14, 39].

Moreover, higher risks are not associated with money paid; they depend on the risk profiles of the donor groups [40]. Still, a significant proportion of the paid donors examined in the studies cited above comes from populations with higher risk profiles, especially from low-income groups, and it is to be expected that payment will continue to attract high-risk donors. Even if all TTIs were detected through rigorous testing, the dropout of blood units is higher in this group than in other donor populations.

\section{Destruction of Altruism/Crowding Out?}

The final, regularly voiced objection against paid donation has again been expressed most prominently by Titmuss. In his work, he argues that a system of paid donation decreases opportunities to behave altruistically and thus harms altruism, while a system without payment fosters altruism in society $[4,5]$. (Altruism is a very complex concept. Several competing definitions of altruism are used in the literature on blood donation. In this paper, a Titmussian definition of altruism - a desire to selflessly help others - shall be presupposed.) More specifically, Titmuss worried that a paid system would have a crowding-out effect on altruistic donors. A crowding-out effect would mean that donation rates actually decrease after the introduction of payment. This would be due to the fact that altruistic donors feel cheated by payment for donation, or feel their altruism was no longer needed, and turn away from donating.
These are both empirical claims rather difficult to prove or disprove. If the first claim about the derogatory effects of paid (and mixed) donation systems on altruism was true, those countries which have had a purely altruistic blood donation system in place for the last decades should show an advantage in terms of altruism within their society. That is, they should have fewer problems to fulfil the demand for blood and have higher organ donation rates and other indicators of high altruism than countries with mixed or paid systems, which have been subject to the harmful effects claimed by Titmuss. So far, an in-depth analysis of whether sales of blood undermine general communal spirit is not available.

As for the crowding out of blood donors, available data is also very scarce. Research from other areas indicates that a crowding-out effect due to payment might occur [41-43], but this cannot be readily transferred to blood donation. In studies asking for future blood donation behaviour, a crowdingout effect has not been shown [44-45]. A study specifically designed to examine crowding out in a real life donation situation has been conducted in Sweden by Mellström and Johannesson. The unpublished data show that a minor crowdingout effect is present in some donor groups. In the study, this crowding-out effect could be countered by the introduction of other forms of incentives (not payment). Quite generally, a crowding out could of course also be potentially offset by a significant increase of the amount of money paid, since it is only present when relatively low sums of money are paid [42].

\section{Preliminary Conclusions}

As can be gathered from this brief description of the most important issues in payment for blood donation, it has remained a difficult challenge to make a fully convincing argument for or against paid donation. Complex underlying philosophical issues - such as what could be considered a coercive offer in rich countries, how to handle certain kinds of payment in the face of existing inequalities in modern societies, or whether there are certain activities and 'goods' which should be exempt from any form of financial transaction - would need to be solved and empirical claims about blood safety and crowding out would have to be proven or disproven before this debate could be clearly decided in favour of one of the competing positions. It is not likely this will happen in the near future.

Hence, at least from a policy perspective, it is important to find a third way which could be considered an acceptable compromise from either perspective. The following parts of this paper will be devoted to a potential candidate for such a compromise, namely the introduction of non-cash incentives of both non-monetary and low monetary value (remember that the latter are goods, vouchers, or services of a certain low value - not cash payments). 


\section{Why Non-Cash Incentives?}

Incentives other than payment have long been a reality in blood donation, but they have seldom been the central focus of the debates about raising donation rates; often, they are simply grouped together with payment. I believe non-cash incentives deserve both a separate discussion and more attention in empirical research.

First of all, with non-cash incentives, it is possible to avoid the theoretical standoff sketched above in the debate about payment, since the arguments discussed above do not apply to non-cash incentives:

\section{Coercion/Pressure}

If it is problematic to clearly show that an offer of money is coercive, it is almost impossible to do so with non-cash incentives. The explicit task of incentives is to make a certain option or activity more attractive. They are aimed at influencing motivation and count as a reason for preferring one choice to the alternative, but they cannot reasonably be considered to be irresistible, especially in well-off countries, where all basic material needs of the population are met. This is partly due to the fact that the liquidity of incentives is far lower than that of money (i.e. they cannot be readily exchanged for any other good and could even be designed not to be exchangeable at all). Moreover, it would be possible to tailor incentives to higher-income groups unlikely to donate out of financial desperation. In these groups, any worry of coercion or pressure due to financial need would be wholly groundless.

\section{Justice}

A similar thought applies to the justice concern some raise in payment, where the fact that poorer people need a payment more than the wealthy is taken to be unfair. Of course the fact remains troubling that large inequalities in income are present in all modern societies. This is an injustice wholly independent from the context of blood donation. While some feel that paying for blood takes advantage of this injustice, few would argue that it is unfair that poorer people find a non-cash incentive of low monetary value more appealing, such as a T-shirt or a ticket voucher - much less an incentive of nonmonetary value, such as social recognition or a peer-signalling effect. Incentives of the latter kind might even be less attractive to those from the lower ranges of the socio-economic ladder. Again, it would be possible to design many different kinds of non-cash incentives, so that for each socio-economic group, there is one which is attractive. With incentives thus being equally attractive to all, the justice concern could be avoided.

\section{Human Dignity/Devaluation}

The matter of harming human dignity through devaluation or group stigmatisation - rather difficult to prove even in payment - does not carry a lot of force in non-cash incentives.
There would be no 'setting a price' on something 'priceless' through incentives, because no 'price' would be paid. With non-cash incentives of many different kinds instead of money, it would also be highly unlikely that accepting one of them for blood donation would subject donors to any kind of shameful acceptance, stigmatisation, or even dehumanisation, especially if proper attention was paid to the setting and the framing of the incentives in question.

\section{Safety}

Systematic data on the disease transmission risk ratio in different kinds of non-cash incentives are still largely lacking. However, some empirical data indicates that unlike cash payment, which is more attractive to low-income groups with higher transmission risks, incentives are not problematic in terms of blood safety, because they are not necessarily tied to such groups with problematic risk profiles [45]. Furthermore, if incentives were made attractive to all kinds of donor groups, the safety concerns relevant in payment would not apply at all.

\section{Altruism}

There is one remaining issue which cannot be circumvented by focusing on non-cash incentives instead of payment: As soon as any kind of incentive is introduced, the donation is no longer purely altruistic, since incentives appeal to other motives. To those who hold that Titmussian selfless altruism must be the only reason for donation no matter the consequences (e.g. die-hard deontologists), any incentive targeting other motives instead of selflessness will always be unethical.

There is no space here for a detailed discussion and refutation of this claim. It shall suffice to say that, firstly, the picture in terms of 'pure' motivation is far muddier when it comes to altruism than its proponents make it out to be: It has been shown that altruistic behaviour is oftentimes also partly motivated by some form of self-interest, and some have questioned whether 'pure' altruism exists at all [46]. Secondly, in liberal modern societies, demanding one supreme motive - or value - for an activity for which several other motives are possible (and present in the population) is fraught with many problems, paternalism being only one of them. Most of those involved in discussing blood donation will not take an extreme position and demand pure selflessness as the only acceptable motive. They will agree that while selfless altruism should always be important in blood donation, other motives are acceptable in addition. These motives could be targeted by a wide variety of different non-cash incentives.

As for the empirical worries, both a destruction of altruism as a value in society as well as a crowding-out effect are highly unlikely consequences of an implementation of non-cash incentives. Non-cash incentives can be used with a lot more variety in setting and choice architecture, and they can even be tied successfully to motives which could be described as largely altruistic, as depicted below. Hence, it can safely be assumed that, with careful attention to the setting and the choice archi- 
tecture in donation, selfless altruism will always remain an important reason to donate. It just will not be the only one.

In sum, there is an argument to be made for non-cash incentives from a theoretical perspective: Carefully framed noncash incentives, which are targeting many kinds of donor groups (with a particular focus on well-off donors) and offered in the right donation setting, avoid most of the complex issues which have remained controversial in the debate about payment for blood donation. They might constitute a 'third way': a workable compromise both sides can agree on without having to yield too much ground in the complex philosophical questions surrounding paid donation.

Secondly, non-cash incentives can also be supported from an empirical perspective: There is a lot of unrealised potential to implement them in very effective ways, and hence, it is very likely that they could significantly increase donation rates [1]. This potential has not been studied with sufficient vigour in blood donation. Below, an interdisciplinary perspective is taken to sketch a comprehensive approach to its realisation.

\section{Beyond 'Altruism versus Payment': Requirements for Policy-Making Using Non-Cash Incentives}

To illustrate the potential of incentives, they should not be discussed as an isolated means to raise donation rates. Instead, they need to be regarded as one factor within a comprehensive approach to that end. It is necessary to re-evaluate some well-established premises of the debate on blood donation, particularly about donor motivation. In addition, donation aspects need to be taken up which have not met with enough attention, such as the choice architecture of donation and donation settings, in order to point out important requirements for successful policy-making.

\section{Donor Motives}

Ever since Titmuss' analysis of two distinct donation systems and the corresponding description of two types of donors, the opposition between altruism in donation on one side and a blood market with economic self-interest on the other has been prominent. Donors and their motivation have frequently been discussed under headings echoing this opposition, such as 'Gift or good?' [35], 'Altruism or payment in blood donation' [11], 'Blood donation - altruism or profit?' [47], or 'Blood: gift or merchandise?' [48]. It also features prominently in regulation and legislation of blood donation.

Above, it has been shown that proposing altruism as the single acceptable normative ideal - namely, as the single alternative to paid donation - is problematic for theoretical reasons. What is more, the dichotomy between paid and altruistic donation also does not properly reflect empirical reality: Titmuss' own methodology and the empirical data he and others use to back up the theoretical emphasis on altruism as both an ideal framework and supreme motive for donation have been challenged [49]. The rather slippery empirical ground Titmuss' hypothesis rests on can also be illustrated by the fact that the evidence on pure altruism and economic self-interest as the two main motives in blood donation has always been unclear - so unclear, in fact, that it is surprising how dominant this dichotomy has remained. Studies from the 1970s up until today have found selfless altruism to be among the important motives for donation [50-54]. Interest in economic gain has been prevalent, too [55-58]. However, at the same time, other reasons and motives for donation have always played an important role as well: Studies have pointed out several important motives which do not fall easily into the dichotomy of pure selfless altruism on one side and selfish interest in financial gain on the other $[50,52,54,56,59]$. These are for example motives such as personal benefit (through many different kinds of goods and rewards), peer pressure and signalling effects (to demonstrate a certain commendable behaviour to peer groups, or to be perceived in a certain way), intrapsychological motives/psychological benefits (such as feeling good about oneself, behaving according to a particular role or self-image), ideas of reciprocity/benevolence (where both donor and recipient benefit), and others [45, 52, 59-64].

Apparently, the dichotomy 'altruism/economic gain' does not capture the reality of donation motives in an adequate way. Focusing on these two - or on one, namely altruism - ignores a whole spectrum of other relevant motives and attitudes.

The dichotomy also does not reflect the actual impact that motives for donation have on predicting and/or causing actual donation behaviour. Several recent studies have shown that altruism, even if present as a motivation, is not strongly related to actual donation behaviour [52, 59, 64]. Other motives seem to be more important for the actual decision and subsequent action of donating blood, and amongst these, financial gain is only one.

And finally, far more studies examining the motivation for donation look at groups of donors than at the non-donating population (exceptions are $[57,63,65,66])$. Since blood donation has been described and publicly called for as an explicitly altruistic activity for decades, it is not surprising that those already donating exhibit altruism as an important motive. It may well be possible that in the far larger non-donor population of modern developed countries, altruism is even less dominant.

In sum, the findings on donation motives do not neatly fall into two opposite categories, nor do they indicate that donors adhere to the ideal of a 'pure' altruistic motivation demanded by most of the current regulation and legislation on blood donation. Instead, they point to a host of different motives influencing the decision to donate. In addition, study results are inconclusive and even apparently conflicting, showing that several different motives probably work at the same time, with some maybe even contradicting each other. This is not really surprising. Why should we expect that donating blood differs 
strongly from other decision-making contexts in life? It is a trivial fact of life that people are very different and that a rich variety of motives and other factors influences decision-making in a pluralistic world, sometimes in rather surprising ways. It would be quite unreasonable to expect that blood donation is the one special instance where one of only two opposing motives dominates the decision-making [62].

From the available empirical studies the conclusion can be drawn that there is a number of motives besides altruism and financial self-interest which could be addressed through noncash incentives. In the present situation of need for blood and little chance of a compromise on paid blood donation, it could be an acceptable compromise to drop the rigid dichotomy and the sole reliance on altruism as the expected reason for donation and start to actively and creatively pursue other motives. In order to successfully raise donation rates, a variety of motives could be addressed, such as benevolence/reciprocity, the need to feel good about oneself, signalling, or personal benefit. Campaigns to attract donors could be tailored far more specifically to groups of donors with some particular motive and/or mixed motives. While campaigns emphasising altruism will find their targets, particularly among the older generations and among those who already donate, other attitudes and motives - and incentives aimed at these - should figure more prominently to attract new donors. The already available research as to which motives are prevalent in which socio-demographic or age group $[45,52,57,63,67]$ can be put to use and should be expanded.

\section{The Choice Architecture of Donation}

Once it has been agreed that it is acceptable to pursue other motives for donation besides altruism, attention needs to be focused on how best to do this. If those parts of the population are targeted which do not already donate, or which have stopped to do so, it is likely that reluctance or laziness to donate is prevalent. How can these obstacles be overcome successfully without, at the same time, exerting unacceptable pressure?

One promising way to do so would involve applying insights not only from psychology and sociology, as has been done before to some extent [59, 62, 64, 68, 69], but also from behavioural economics and marketing. Titmuss' description of blood donation as the one rare occasion of and opportunity for altruism paved the way for blood donation mostly being discussed as a very special kind of behaviour. But, as has been alluded to in the discussion of donor motives: this is not necessary. While donating blood certainly has some unusual features, there is little reason to assume that it can be exempted from the rules which govern all other kinds of behaviours (for an in-depth discussion of related pro-social behaviours, see [70]). On the contrary, looking at these rules and defaults more closely could provide insights beneficial to improving donation programmes. In this respect, recent work on behavioural economics is instructive [71]. During the last decades of psychological and sociological research on human behaviour and decision-making, a large variety of behaviour-influencing factors have been found to be at work both in everyday life and in difficult and unusual situations. Together, these factors can be labelled as the architecture of choice. Some of the strongest influences on our decisions are inertia and laziness. No matter which area (social policy and welfare, health care, private or social investment, or marketing): If a program wants to succeed in making a certain choice attractive, one of the most important tasks is to overcome this reluctance to decide and act.

New approaches to successful behaviour modification claim not to fall prey to the charge of unduly pressuring people and taking away their right to freely choose what they want to do. Instead, these approaches use 'nudges'. Nudges are changes to the choice architecture which make use of the various factors influencing behaviour and, in this way, succeed in steering people towards a desired decision, while still preserving unrestricted and free choice. To reflect the freedom of choice combined with the explicit goal to get people to do things which are deemed to be good or to benefit them, the theoretical framework of these accounts is called libertarian paternalism; libertarian, because choices are free and not restricted; paternalism, because changes in the choice architecture are used explicitly to influence people's decisions 'for their own good'.

Several of the findings from behavioural economics are relevant to the context of donating blood. To mention just a few:

- Human choices are remarkably susceptible to the manner in which options are presented (framing effect). By changing the schema of interpretation - the frame -, decisions can be selectively influenced.

- Irrespective of rational reasoning, people have an in-built, automatic desire to behave in the way others behave (conformity effect). By informing people what others do, or what some particular group does, it is possible to steer decisions in a desired direction.

- People's decisions also strongly follow primes, i.e. associative cues and other 'channel factors' that facilitate or inhibit behaviour. For example, measuring people's intention and then reminding them of it works very well towards influencing a particular decision (mere measurement effect).

- Finally: Incentives work. Particularly when they are specifically tailored to motives people have and combined with other nudges, such as framing or peer pressure, incentives are among the strongest factors influencing behaviour, without at the same time being coercive.

Individually, these and many other findings are not new, nor are they really surprising. What is surprising, however, is that they have not been put to use systematically to help increase blood donation. Many ideas for nudges exist as well as the respective research to back them up. Several ways of shaping the choice architecture are known to work in many areas of 
social policy, such as social security, preservation of the environment, drug policy, education, marriage etc. [71]. Some of these ideas could be used in blood donation.

For instance, there are several ways to frame blood donation. In the past, the dominant perspective and interpretative framework for blood donation has been selfless altruism, and hence donating blood has mostly been framed as an altruistic activity. However, many other frames are possible which need not involve the established opposite of altruism, namely cold financial self-interest. Blood donation could be framed as brave, or as heroic, or as clever in serving your self-interest, or as something to be proud of, or as a reciprocal and benevolent give and take, or as several of these aspects at once. All the motives which have been shown to be relevant in empirical research could be mined for their suitability in framing donation for different groups of donors, both separately and in combination; new motives could be tried out. Why not try to frame blood donation as 'cool', or as 'hip', or as something that all your friends do?

In a similar vein, mild peer pressure and conformity effects could be used to encourage - nudge - people to donate. For example, donors could get a reward (e.g. an incentive of the kind mentioned below) if they bring friends with them to donate or if they persuade their co-workers to give blood. Awards could be implemented for companies, sports clubs, school classes etc. who have very high donation rates. Online social networks such as Facebook, Twitter, LinkedIn etc. would not only be helpful tools in framing donation in new ways to attract new groups of potential donors, but could also be used to spread the information of how many people actually already donate, who is a 'fan' of the 'I donate blood' group, what incentives are available, where donation sites are located etc. Today, most people do not know if their neighbours, co-workers, or acquaintances donate blood. In order to activate the conformity effect, donor names could be published in local newspapers or read out at social occasions - not unlike the names of those who donate to charities or support social and cultural institutions (of course, donor consent to this would have to be gained).

Finally, the mere measurement effect has, under a different label, already been shown to work in blood donation. The professed intention to donate is one of the best factors to predict donor retention [59]. Asking the whole population whether they intend to donate blood in the future at some obligatory event (such as getting an identity card/passport) could make use of the mere measurement effect as well as raise awareness of the need for donation.

In sum: The many motives people have for donating could be used to frame and prime donation and tailor campaigns to specific donor groups. Mild peer pressure, conformity, mere measurement effects, and other nudges could all inform the design of these campaigns. The final and most important element would then be the introduction of adequate non-cash incentives. These could both have some or no monetary value, depending on the motive they would try to appeal to - in any case, they would have to be specifically designed and tailored to the choice architecture. Young donors attracted through Facebook groups will be interested in other incentives than members of a local chess club. Marketing experts have been devising tailored incentives for a long time when trying to sell products to different groups of users, consumers, or customers. Their experience could be employed in developing choice architecture for blood donation which is informed both by decades of research in human psychology as well as by the empirical evidence from studies in the donation context.

In using nudges (including non-cash incentives) to tailor donation campaigns to people with different motives, an important worry mentioned above could disappear, namely that incentives are more attractive to low-income donors. In marketing, for example, bonus programs have been developed which appeal to many groups of customers, and particularly to those above a certain income threshold. (An example is the German 'payback loyalty card', which awards points for certain purchases (www.payback.de). These points can be collected and exchanged for a great variety of goods/rewards, several of which are especially attractive to higher-income people. Moreover, the rather complicated procedure of collecting and exchanging the points is apparently used less by people from the lowest socio-economic groups.) It would be possible to devise such programs for blood donation.

It should also be stressed that in keeping with the theory of libertarian paternalism, none of the described avenues of influencing behaviour and steering people towards a particular decision involves any coercion or undue pressure. What the approach does involve is the use of insights into behavioural psychology to affect decisions - without making anyone do anything against their will.

\section{Donation Setting}

The final element of a comprehensive approach to incentives for blood donation is setting. Most choices take place within a certain social situation. Apart from the elements of choice architecture described above, whether motives actually lead to the intended action also to some degree depends on the social setting of that action. The importance of setting has been recognised in other areas. For example, the concept has been used to develop the 'setting approach of health promotion' by the WHO [72-74]. A setting in this context is defined as 'a socially and culturally defined geographic and physical area of social interaction, and a socially and culturally defined set of patterns of interactions performed in the area' [74]. Within a setting, and through shaping particular aspects of a setting (such as institutions and environments), interactions can be changed and improved, behaviours influenced, and decisionmaking modulated.

So far, there has not been a lot of emphasis on the importance of setting in blood donation. A few setting factors have been studied (sometimes under the rather misleading head- 
ing of donor motivation): general availability, opening hours, convenience of donation sites, friendliness of staff, and availability and quality of information about health risks or potential pain $[61,62,65,75-77]$. There is also some evidence of the general importance of institutional setting on donation rates [71]. This research should be expanded and results implemented - with the goal to make the donation experience as agreeable as possible. Using experiences from health promotion-setting experiments could further help remove obstacles and barriers to donating more effectively than in the past.

Whether and how exactly blood donation can properly be described as a particular setting shall be left to the experts in setting approaches. Certainly, the general idea of a social setting providing important channels of influence on people applies to the blood donation context, and it lends itself very well to combining it with approaches to change the architecture of choice, as outlined above.

\section{What Kind of Incentives?}

Non-cash incentives in blood donation have been discussed for a long time, albeit without particular attention to the supporting factors described above. Ranging from tokens of appreciation (medals, certificates) to goods and gifts (T-shirts, mugs, food, vouchers to stores or restaurants etc.), many have been shown to work [45]. The argument laid out in the previous sections justifies intensified research devoted to both old and new non-cash incentives and how they could work as part of a well-designed and specifically tailored choice architecture and donation setting. Younger donor populations might, e.g., be more attracted to vouchers for songs on iTunes, mobile phone ring tones or mobile phone credits, video game bonuses, or software, while other groups might like a voucher for a wellness or health class, tickets to the theatre, museums, lectures, or a restaurant voucher. Others might be drawn to a mark of public recognition, such as their name being put on public display - in a ticker on TV or online, printed in a newspaper, or read out in a radio show or at some community event. Charity donations in their name will be appealing to some groups of donors; others will prefer to collect points for donating on the 'blood donation loyalty card' and exchange these points for any of the incentives mentioned. Donorexclusive T-shirts designed by a well-known designer (but, of course, mass-produced and rather cheap), or signed by a Hollywood star, would be attractive to some, whereas others might enjoy a rock event or a classical concert with a famous musician to which only donors can buy tickets.

Beyond what has been discussed in the literature already, there are many opportunities to imagine non-cash incentives, and marketing experts could lend a hand at developing them. If accompanied by proper framing, in keeping with the multitude of donation motives, none of them need to reflect the old 'cold-hearted economic self-interest'. Instead, they could mirror the complexity of real choice and the mixture of motives. They could appeal to altruism while at the same time recognising that other motives, including personal interest, are also acceptable and justified in blood donors. Example: A campaign framing donation as a benevolent give and take, with both altruistic aspects as well as warranted self-interest, and an incentive - for instance a ticket voucher for a classical concert or a wellness class - as a reward (one possible slogan: 'You have made my treatment possible. Now you go treat yourself.'). Such a campaign could attract many well-off donors without destroying the altruistic component of their motivation. The gratefulness expressed might also preserve signalling effects while the reward appeals to a justified selfinterest.

\section{Conclusion}

In this paper, non-cash incentives have been sketched as a possibility to find a middle way between the two established theoretical frameworks for donation (exclusive reliance on altruism on one side and payment on the other). Some suggestions how to exploit the potential of incentives to raise donation rates as part of a comprehensive approach have also been given. This approach includes paying attention to donor motives as well as to the architecture of choice and donation setting.

The important question of whether the incentives discussed in this paper violate national and international regulation and legislation has not been taken up. Moreover, nothing has been said about how well different existing donation systems, e.g. fully altruistic systems (such as in the UK) or mixed systems (such as in the US), would lend themselves to the implementation of the approach developed above. Interdisciplinary work, more research, and money are necessary, both to successfully tackle these remaining issues in policy-making as well as to implement the suggestions. It will also take time and effort. The goal of providing a safe and sufficient blood supply might make it worth it.

\section{Acknowledgements}

I thank Nir Eyal for stimulating discussions on incentives and comments on an early version of this manuscript, and Gustav Tinghög and Daniel Friedrich for helpful comments on earlier versions of this manuscript.

\section{Disclosure}

The author declared no conflict of interest. 


\section{References}

1 Jones RL: The blood supply, from donor to patient: a call for greater understanding leading to more effective strategies for managing the blood supply. Transfusion 2003;43:132-135.

2 Duncan RE, Delatycki MB, Collins SJ, Boyd A, Masters CL, Savulescu J: Ethical considerations in presymptomatic testing for variant CJD. J Med Ethics 2005;31:625-630.

3 Hart J, Leier B, Nahirniak S: Informed consent for blood transfusion: should the possibility of prion risk be included? Transfus Med Rev 2004;18:177183.

4 Titmuss RM: The Gift Relationship. From Human Blood to Social Policy, ed 2, expanded. New York, New Press, 1997.

5 Titmuss RM: Why give to strangers? Lancet 1971;1: 123-125.

6 Keown J: The gift of blood in Europe: an ethical defence of EC directive 89/361. J Med Ethics 1997; 23:96-100.

7 McLachlan HV: The unpaid donation of blood and altruism: a comment on Keown. J Med Ethics 1998;24:252-254.

8 Keown J: A reply to McLachlan. J Med Ethics 1998; 24:255-256.

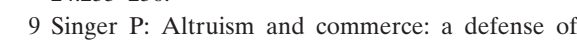
Titmuss against Arrow. Philos Public Aff 1973;2: 312-320.

10 Rodriguez del Pozo P: Paying donors and the ethics of blood supply. J Med Ethics 1994;20:31-35.

11 Fernández-Montoya A: Altruism and payment in blood donation. Transfus Sci 1997;18:379-386.

12 Whyte G: Ethical aspects of blood and organ donation. Int Med J 2003;33:362-364.

13 Archard D: Selling yourself: Titmuss's argument against a market in blood. J Ethics 2002;6:87-103

14 Mascaretti L, James V, Barabara J, Cardenas JM, Blagoevska M, Haracic M: Comparative analysis of national regulations concerning blood safety across Europe. Transfus Med 2004;14:105-111.

15 EU: Directive 2002/98/EC of the European Parliament and Council 27 January 2003. Official Journal of the European Union 2003;L33:30-40.

16 Beal R: The International Society of Blood Transfusion and A Code of Ethics for Blood Donation and Transfusion. Vox Sang 2002;82:166.

17 Council of Europe: Guide to the Preparation, Use, and Quality Assessment of Blood Components, ed 13. Strasbourg, Council of Europe Publishing, 2007.

18 WHO: Universal access to safe blood transfusion. 2008. www.who.int/bloodsafety/en.

19 Marckmann G: Human blood: altruistic donation for commercial purposes? (in German); in Taupitz J: Kommerzialisierung des menschlichen Körpers. Berlin, Springer, 2008, pp 69-81.

20 Faden RR, Beauchamp TL: A history and theory of informed consent. New York, Oxford University Press, 1986.

21 Beal RW, van Aken WG: Gift or good? Vox Sang 1992;63:1-5.

22 Nozick R: Coercion; in Morgenbesser S, Suppes P, White M: Philosophy, Science, and Method: Essays in Honor of Ernest Nagel. New York, St. Martin's Press, 1969, pp 440-472.

23 Feinberg J: Harm to Self. New York, Oxford University Press, 1986.

24 Wertheimer A: Coercion. Princeton, Princeton University Press, 1987.

25 Fowler M: Coercion and practical reason. Soc Theo Prac 1982:8:329-355.
26 WHO: Blood transfusion safety. 2008. www.who int/bloodsafety/en/Blood_Transfusion_Safety.pdf.

27 Cohen IG: Note: The price of everything, the value of nothing: reframing the commodification debate. Harv Law Rev 2003;117:689-710.

28 Veatch RM: Why liberals should accept financial incentives for organ procurement. Kennedy Inst Ethics J 2003;13:19-36.

29 Morelli M: Commerce in organs: a Kantian critique. J Soc Philos 1999;30:315-324.

30 Satz D: Noxious markets: why should some things not be for sale?; in Pattanaik P, Cullenberg S: Economic Theory, Philosophy and Contemporary Social Issues. New Delhi, Oxford University Press, 2003, pp 11-38.

31 Sandel M: What money can't buy: the moral limits of markets; in Peterson GB: The Tanner Lectures on Human Values, vol 21. Salt Lake City, University of Utah Press, 2000.

32 Radin M: Contested Commodities. Cambridge, MA, Harvard University Press, 1996

33 Eastlund T: Monetary blood donation incentives and the risk of transfusion-transmitted infection. Transfusion 1998;38:874-882.

34 Kalibatas V: Payment for whole blood donation in Lithuania: the risk for infectious disease markers. Vox Sang 2008;94:209-215.

35 Van Aken WG: Gift or good? (in French). Transfus Clin Biol 2006;13:196-199.

36 McFarland JG, Aster RH, Buggy BP: Paid time off for blood donation - an incentive to be less than truthful? Transfusion 1997:37:447-448.

37 Chitwood DD, Page JB, Comerford M, Inciardi JA, McCoy CB, Trapido E, Lai SH: The donation and sale of blood by intravenous drug users. Am J Public Health 1991;81:631-633.

38 Zou S, Notari EP 4th, Musavi F, Dodd RY; ARCNET Study Group: Current impact of the confidential unit exclusion option. Transfusion 2004;44:651657

39 Willand L, Ritter S, Reinhard B, Offergeld R, Hamouda O: HIV, HCV, HBV and syphilis infections among blood donors in Germany 2006. Report from the Robert Koch Institute in accordance with Article 22 of the Transfusion Act (in German). Bundesgesundheitsbl Gesundheitsforsch Gesundheitsschutz 2008;51:902-914.

40 Strauss RG: Blood donations, safety, and incentives. Transfusion 2001;41:165-167.

41 Frey BS, Oberholzer-Gee F, Eichenberger R: The old lady visits your backyard: a tale of morals and markets. J Polit Econ 1996;104:1297-1313.

42 Gneezy U, Rustichini A: Pay enough or don't pay at all. Q J Econ 2000;115:791-810.

43 Gneezy U, Rustichini A: A fine is a price. J Legal Stud 2000;29:1-17.

44 Jones RP, Prasad V, Kuruvatti J, Tahir N, Whitaker P, Dawson AS, Harrison MA, Williams R: Remuneration for blood donation and attitudes towards blood donation and receipt in Leeds. Transfus Med 2003;13:131-140.

45 Glynn SA, Williams AE, Nass CC, Bethel J, Kessler D, Scott EP, Fridey J, Kleinman SH, Schreiber GB; Retrovirus Epidemiology Donor Study: Attitudes toward blood donation incentives in the United States: implications for donor recruitment. Transfusion 2003;43:7-16.

46 Harbaugh TW: What do donations buy? A model of philanthropy based on prestige and warm glow. J Public Econ 1998;67:269-284.

47 Oakley A: Blood donation - altruism or profit? BMJ 1996;312:1114.
48 Hagen PJ: Blood: Gift or Merchandise? Towards an International Blood Policy. New York, Alan R. Liss, 1982.

49 Rapport FL, Maggs CJ: Titmuss and the gift relationship: altruism revisited. J Adv Nurs 2002;40: 495-503.

50 Alessandrini M: Community volunteerism and blood donation: altruism as a lifestyle choice. Transfus Med Rev 2007;21:307-316.

51 Sojka BN, Sojka P: The blood donation experience: self-reported motives and obstacles for donating blood. Vox Sang 2008;94:56-63.

52 Steele WR, Schreiber GB, Guiltinan A, Nass C, Glynn SA, Wright DJ, Kessler D, Schlumpf KS, Tu Y, Smith JW, Garratty G; Retrovirus Epidemiology Donor Study: Role of altruistic behavior, empathetic concern, and social responsibility motivation in blood donation behavior. Transfusion 2008;48:43-54.

53 Misje AH, Bosnes V, Gasdal O, Heier HE: Motivation, recruitment and retention of voluntary nonremunerated blood donors: a survey-based questionnaire study. Vox Sang 2005;89:236-244.

54 Oswalt RM: A review of blood donor motivation and recruitment. Transfusion 1977;17:123-135.

55 Marantidou O, Loukopoulou L, Zervou E, Martinis G, Egglezou A, Fountouli P, Dimoxenous P, Parara M, Gavalaki M, Maniatis A: Factors that motivate and hinder blood donation in Greece. Transfus Med 2007;17:443-450.

56 Trimmel M, Lattacher H, Janda M: Voluntary whole-blood donors, and compensated platelet donors and plasma donors: motivation to donate, altruism and aggression. Transfus Apher Sci 2005;33: 147-155.

57 Tscheulin DK, Lindenmeier J: The willingness to donate blood: an empirical analysis of socio-demographic and motivation-related determinants. Health Serv Manage Res 2005;18:165-174.

58 Zeiler T, Kretschmer V: Survey of blood donors on the topic of 'reimbursement for blood donors' (in German). Infusionsther Transfusionsmed 1995;22: 19-24.

59 Schlumpf KS, Glynn SA, Schreiber GB, Wright DJ, Randolph Steele W, Tu Y, Hermansen S, Higgins MJ, Garratty G, Murphy EL; National Heart, Lung, and Blood Institute Retrovirus Epidemiology Donor Study: Factors influencing donor return. Transfusion 2008;48:264-272.

60 Roberts RD, Wolkoff MJ: Improving the quality and quantity of whole blood supply: limits to voluntary arrangements. J Health Polit Policy Law 1988; 13:167-178.

61 Zaller N, Nelson KE, Ness P, Wen G, Bai X, Shan $\mathrm{H}$ : Knowledge, attitude and practice survey regarding blood donation in a Northwestern Chinese city. Transfus Med 2005;15:277-286.

62 Belda Suárez IM, Fernández-Montoya A, Rodríguez Fernández A, López-Berrio A, Cillero-Peñuela M: How regular blood donors explain their behavior. Transfusion 2004:44:1441-1446.

63 Nonis SA, Ford CW, Logan L, Hudson G: College student's blood donation behavior: relationships to demographics, perceived risk, and incentives. Health Mark Q 1996;13:33-46.

64 Ferguson E, Farrell K, Lawrence C: Blood donation is an act of benevolence rather than altruism Health Psychol 2008:27:327-336.

65 Godin G, Sheeran P, Conner M, Germain M, Blondeau D, Gagné C, Beaulieu D, Naccache H: Factors explaining the intention to give blood among the general population. Vox Sang 2005;89:140-149. 
66 Leibrecht BC, Hogan JM, Luz GA, Tobias KI: Donor and nondonor motivations. Transfusion 1976;16: 182-189.

67 Glynn SA, Schreiber GB, Murphy EL, Kessler D, Higgins M, Wright DJ, Mathew S, Tu Y, King M, Smith JW; Retrovirus Epidemiology Donor Study: Factors influencing the decision to donate: racial and ethnic comparisons. Transfusion 2006;46:980-990.

-68 Jason LA, Jackson K, Obradovic JL: Behavioral approaches in increasing blood donations. Eval Health Prof 1986;9:439-448.

69 Healy K: Embedded altruism: blood collection regimes and the European Union's donor population. Am J Sociol 2000;105:1633-1658.

70 Bénabou R, Tirole J: Incentives and prosocial behaviour. Am Econ Rev 2006;96:1652-1678.

71 Thaler HT, Sunstein CR: Nudge: Improving Decisions about Health, Wealth, and Happiness. New Haven, Yale University Press, 2008.

72 Baric L: The settings approach - implications for policy and strategy. J Inst Health Educ 1993;31:1724.

73 Whitelaw S, Baxendale A, Bryce C, MacHardy L, Young I, Witney E: 'Settings' based health promotion: a review. Health Promot Int 2001;16:339-353.

74 Wenzel E: A comment on settings in health promotion. Internet J Health Promot 1997. http://rhpeo. net/ijhp-articles/1997/1/index.htm.

75 Martín-Santana JD, Beerli-Palacio A: Potential donor segregation to promote blood donation. Transfus Apher Sci 2008;38:133-140.

76 Hupfer ME, Taylor DW, Letwin JA: Understanding Canadian student motivations and beliefs about giving blood. Transfusion 2005;45:149-161.

77 Ford GT, Wallace EL: Effects of donor recruitment methods on population responses. Transfusion 1975;15:159-164. 